\title{
La constitucionalización del derecho fundamental a la IVE, hacia lo que la interpretación aclara y lo que oscurece de la internacionalización del derecho a nacer
}

\author{
Fernando Guerrero Cárdenas \\ Abogado Especialista en Derecho Administrativo y en Derecho Constitucional por la Universidad Santo Tomás \\ Seccional Bucaramanga, Colombia. Magíster en Litigio Internacional en DH y DIH por la Universidad Santo Tomás \\ Seccional Bogotá, Colombia. Doctorando en Derecho en la Universidad Externado de Colombia, Bogotá. \\ Docente Universidad Santo Tomás, Bucaramanga. \\ Correo electrónico: fernandoguerreroc@hotmail.com. \\ Yudi Maquiud Vanegas \\ Abogada por la Universidad Santo Tomás Seccional Bucaramanga, Colombia. Especialista en Derecho Constitucional. \\ Correo electrónico: yudimaquiud@gmail.com
}

\begin{abstract}
Resumen
En este escrito se reconstruye la constitucionalización del derecho fundamental a la interrupción voluntaria del embarazo, teniendo como referente la sentencia de la Corte Constitucional colombiana post C-355 de 2006 que da un giro interpretativo y proporciona los elementos para su desarrollo, fundamentación y concreción, para un examen de los argumentos especialmente al enfrentar la tensión con el principio, derecho humano y garantía de protección del derecho a nacer recientemente incorporado en la justicia global internacional, especialmente del que es diferente.
\end{abstract}

Palabras clave: IVE, derecho a nacer, nasciturus, reconstrucción, dogmática, constitucionalización.

\begin{abstract}
In this paper reconstructs the fundamental right to abortion, taking as reference the judgments of the Constitutional Court of Colombia 1996 post-355 that develop, based on and realized, for a discussion of the arguments especially when faced with stress the beginning, human right protection guarantee of the right to birth newly incorporated in the international global justice, especially that which is different.
\end{abstract}

Keywords: IVE, Law born, Unborn, Reconstruction, Dogmatic, Constitutionalization.

\section{Résumé}

Dans cet article, la constitutionnalisation du droit fondamental à l'avortement est reconstruite, en prenant comme référence les arrêts de la Cour constitutionnelle colombienne C- 355 après 2006 qui donne une rotation d'interprétation et de fournir les éléments pour le développement, de fondation et concret, pour une discussion des arguments en particulier dans le visage de tension avec le principe, les droits humains et la garantie de la protection du droit à récemment intégré dans la justice mondiale internationale, en particulier celle qui est la naissance différente.

Mots-clés: IVE, Droit à la naissance nasciturus, la reconstruction, dogmatique, constitutionnalisation. 



\section{La constitucionalización del derecho fundamental a la IVE, hacia lo que la interpretación aclara y lo que oscurece de la internacionalización del derecho a nacer ${ }^{*}$}

Fernando Guerrero Cárdenas

Yudi Maquiud Vanegas

\section{INTRODUCCIÓN}

\section{Implicación perlocucionaria}

A nuestro Padre, a nuestros padres, a nuestras hijas, a nuestros familiares, a nuestro amigo Wilson, y a nuestra Universidad, todo nuestro esfuerzo y alegrías".

Recientemente la Corte Constitucional colombiana ha asentado su jurisprudencia sobre la interpretación constitucional relacionada con los derechos de las mujeres frente a un embarazo con las características desarrolladas en la Sentencia C-355 de 2006 ${ }^{1}$. Es sabido que desde el año 2006, vía interpretación constitucional justiciable, se asumió la recomendación del Comité de Derechos Humanos del 2004 de despenalizar el aborto en ciertas circunstancias.

Luego, del mismo modo, una pequeña cascada de sentencias de la Corte llevaron a concebir como derecho fundamental la Interrupción Voluntaria del Embarazo $(\mathrm{IVE})^{2}$. Esto generó unos problemas, teóricos, axiológicos, ontológicos, e incluso morales y éticos, desde luego, dado las faltas del discurso pragmático propio del plano práctico de la administración de justicia, o de la dogmática en sede judicial.

\footnotetext{
El presente escrito se realiza desde la asignatura Metodología de la Investigación en la Especialización en Derecho Constitucional de la Universidad Santo Tomás Bucaramanga

1 Sexto Informe Periódico del Comité de Derechos Humanos de la ONU del 4 de agosto de 2010, producido conforme al Pacto Internacional de Derechos Civiles y Políticos suscrito entre otros por Colombia, en evaluación especialmente de los artículos 3, 6 y 26.

2 Se propone desde la tesis sobre el poder constituyente en manos de cortes constitucionales, qué casos fundamentalmente constitucionales, por vacíos legales y omisiones parlamentarias, han sido construidas en sede judicial, como en el caso de lo relacionado con la familia. Al respecto ver David Franco (2012).
} 
En este escrito se pretende realizar un acercamiento descriptivo de la jurisprudencia para proporcionar cierto material ${ }^{3}$ y así asumir, en otro momento, el problema sobre si la construcción del derecho fundamental a la IVE, consolidada como doctrina constitucional, cumple con los desafíos teórico-morales y éticos, que desde una perspectiva de la protección del derecho a nacer del nasciturus-tradicionalmente discriminado y excluido de las categorías de los sujetos de derecho junto a las teorías subjetivas del derecho- ha sido trasladados a la ciencia del derecho, al derecho que es, y si se quiere, al derecho que debe ser.

Por lo tanto, para este acercamiento se reconstruirán las premisas de la construcción de este derecho (IVE) concretado en sede judicial constitucional, describiendo los elementos que paso a paso delinearon su alcance y su sentido, para esto se partirá de un estudio de la Sentencia C-355 de 2006 para luego adelantar en detalle la jurisprudencia que desarrolló sus elementos, por último, simplemente se planteará un ejemplo que podría destruir o tensionar, las premisas proporcionadas por la construcción de la Corte, y que parte de la perspectiva de obligación de protección del derecho a nacer, específicamente de quien es diferente y en su niñez tradicionalmente discriminado.

\section{LA PRÁCTICA Y LA TEORÍA EN LA SENTENCIA C-355 DE 2006}

La vida como categoría jurídica es una construcción permanente que implica, desde la axiología, riesgos de extinción de los postulados que solía proteger, incluso actualmente algunos de estos postulados rechazan la vida como "vida natural". Dworkin (2003) ha señalado que frente a los nuevos desafíos al derecho, la teoría y la práctica de los derechos, se tiene la tarea a asumir, un poco desarrollando la tesis katiana (Carrillo, 2009). A pesar de que las críticas a Dworkin se desarrollan con alguna velocidad y verdad, su tesis que sirve o alimenta a ideologías contrarias a la suya, impone cierta carga, la cual debe de asumir tanto sus contradictores como sus seguidores. Por tal razón, se asume como imperativo el compromiso, pero dado los resultados del estudio, se invertirán los factores:

\section{Práctica: razones en la Sentencia C-355 de 2006}

El Estado colombiano, vía judicial, resolvió las perplejidades relacionadas con las tensiones de los derechos humanos sexuales y reproductivos ${ }^{4}$ frente al derecho

3 Un trabajo de recopilación de artículos sobre reconstrucciones jurisprudenciales, similar al objetivo de la Especialización en Constitucional de la Universidad Santo Tomás, es abordado en "Hacia un nuevo derecho constitucional" del Observatorio de Justicia Constitucional, de Bonilla y Iturralde (2005) donde se compilaron varios escritos de este tipo realizados por profesores de la Facultad de Derecho de la Universidad de los Andes, en específico respecto a tres tipos de relaciones con el derecho, abordados por la Corte Constitucional.

4 Las obligaciones internacionales del Estado colombiano en relación con la promoción y protección de los derechos sexuales y reproductivos, se desprenden principalmente de la Convención sobre la 
de nacer del nasciturus. Se puede afirmar que a partir del año 2006, la Corte Constitucional cambió el paradigma sobre el delito de aborto y dio las bases para la constitucionalización ${ }^{5}$ de nuevos derechos; un examen preliminar a sus elementos permitirá a futuro detallar sus falencias o imprecisiones teóricas, y las fallas en asumir la relación del derecho con la moral.

Un primer elemento puede estar relacionado con el mito de lo emblemático de la estructura de la Sentencia, específicamente con que se estableció doctrina en 700 páginas $^{6}$ (realmente son 689 ). Su extensión responde principalmente a la siguiente descripción: 17 páginas relativas a su introducción ${ }^{7}$; 17 donde se describen los aspectos más relevantes de las demandas de inconstitucionalidad presentadas; 131 para las intervenciones ${ }^{9}$ (incluyendo las extraordinarias y extranjeras); 40 que relatan los aspectos generales del Concepto 4024 del 1 de febrero de 2006, del

Eliminación de todas las Formas de Discriminación contra la Mujer, de la ONU, adoptada por la Asamblea General, según Resolución No. 34/180, del 18 de diciembre de 1979, que entró en vigor el 3 de septiembre de 1981. La CEDAW estipula la siguiente obligación para los Estados partes, entre ellos Colombia, respecto a los derechos sexuales y reproductivos: "Artículo 5. [Los Estados se obligan:] ... a) Modificar los patrones socioculturales de conducta de hombres y mujeres, con miras a alcanzar la eliminación de los prejuicios y las prácticas consuetudinarias y de cualquier otra índole que estén basados en la idea de la inferioridad o superioridad de cualquiera de los sexos o en funciones estereotipadas de hombres y mujeres; b) Garantizar que la educación familiar incluya una comprensión adecuada de la maternidad como función social y el reconocimiento de la responsabilidad común de hombres y mujeres en cuanto a la educación y al desarrollo de sus hijos, en la inteligencia de que el interés de los hijos constituirá la consideración primordial en todos los casos". Por su lado, el artículo 16 de la misma, obliga a los Estados parte a adoptar "todas las medidas adecuadas para eliminar la discriminación contra la mujer en todos los asuntos relacionados con el matrimonio y las relaciones familiares y, en particular, asegurarán en condiciones de igualdad entre hombres y mujeres: (...) d) Los mismos derechos y responsabilidades como progenitores, cualquiera que sea su estado civil, en materias relacionadas con sus hijos; en todos los casos, los intereses de los hijos serán la consideración primordial...

5 Ver una posición sobre la constitucionalización en Fernando Guerrero (2013).

6 Sitio web de la Corte Constitucional Colombiana que anexa el texto oficial de la Sentencia C-355 de 2006. Recuperado de http://www.corteconstitucional.gov.co/relatoria/2006/C-355-06.htm

7 Se relacionaron las normas demandadas por inconstitucionalidad del Código Penal: Numeral 7 del artículo 32 relativo a la ausencia de responsabilidad penal cuando se obre por la necesidad de proteger un derecho propio o ajeno de un peligro actual o inminente; el artículo 122 relativo al reproche penal a la mujer y al sujeto que causare aborto; el artículo 123 relativo al aborto sin consentimiento; el artículo 124 sobre las circunstancias de atenuación punitiva en tres cuartas partes cuando el aborto se produzca por embarazo resultado de una conducta constitutiva de acceso carnal o acto sexual sin consentimiento, abusivo, de inseminación artificial o transferencia de óvulo fecundado no consentidas.

8 Demandas de Mónica del Pilar Roa López, Pablo Jaramillo Valencia, Marcela Abadía Cubillos, Juana Dávila Sáenz y Laura Porras Santanilla.

9 Intervenciones del Instituto Colombiano de Bienestar Familiar-ICBF-; La Corporación Casa de la Mujer de Bogotá; Corporación Cisma Mujer; Defensor del Pueblo; Ministerio de Protección Social; Conferencia Episcopal Colombiana; Universidad Santiago de Cali; Academia Nacional de Medicina; Miembros de la Iglesia Cristiana Carismática Tabernáculo de la Fe; Intervención de Rafael Nieto Navia y otros; David Pérez Palacio miembro de la Red Latinoamericana de Abogados Cristianos y de la red de abogados Advocates International; y otros. 
Procurador General ${ }^{10}$; un poco menos de 100 páginas para las consideraciones de la Corte Constitucional, la cual a su vez dedicó 14 para el estudio de los impedimentos y posibles nulidades del proceso y 10 páginas para la descripción del asunto y el estudio de posible cosa juzgada ${ }^{11}$.

La Corte Constitucional en menos de 80 páginas esboza su tesis, la cual parte de un examen al derecho a la vida como un bien constitucionalmente relevante y su diferencia frente al derecho a la vida ${ }^{12}$; como un segundo punto, se examina la vida del nasciturus frente a la protección de los instrumentos internacionales, específicamente respecto al Pacto Internacional de Derechos Civiles y Políticos, la Convención de los Derechos del Niño ${ }^{13}$ y la Convención Americana de Derechos Humanos; en un tercer punto, se analiza los derechos de las mujeres en la Constitución y en el Derecho Internacional; un amplio espacio relacionado con los límites a la potestad de configuración del legislador en materia penal; un quinto tema relacionado con el aborto en el derecho comparado; un penúltimo tema fue el examen al caso concreto; y finalmente, las consideraciones finales. Esta descripción preliminarmente indica dos posturas: la primera que la razonabilidad de la doctrina ${ }^{14}$ es menos extensa de lo

10 El Procurador General de la Nación, Doctor Edgardo José Maya Villazón, dividió el concepto en 10 partes, solicitando a la Corte la exequibilidad condicionada del artículo 122 de la Ley 599 de 2000cuando se presenten los casos de i) concepción no consentida por la mujer, ii) en embarazos con grave riesgo para la vida o la salud física o mental de la mujer, y el iii) establecimiento médico de la existencia de enfermedades o disfuncionalidades del feto que le hagan inviable. Dividió sus razones en 10 partes así: 1. Problema jurídico; 2. Aclaración previa (donde señala que el concepto expresa lo antes presentado dentro del expediente que dio origen a la sentencia inhibitoria C-1299 de 2005); 3. Inexistencia de cosa juzgada constitucional; 4. Determinación de la constitucionalidad de una norma (confrontación con la CN y los tratados internacionales de DDHH); 5. La dignidad humana como parámetro para resolver la tensión que se presenta en la norma acusada; 6 . El bloque de constitucionalidad; 7. Los derechos fundamentales asociados a la interrupción voluntaria del embarazo en la Constitución colombiana y en las normas internacionales; 8. La política en torno al aborto; 9. Los criterios que determinan la constitucionalidad de la política criminal; 10. El aborto con consentimiento en menor de catorce años.

11 Adicionalmente la Sentencia relaciona en 386 páginas, las aclaraciones y salvamentos de voto.

12 La diferencia parte para la Corte de un aspecto histórico. Advierte que la vida como derecho, es una inclusión al mundo jurídico relativamente reciente que data de finales de la Segunda Guerra Mundial, que tiene como precursor la Ley Fundamental de Bonn. El derecho a la vida a pesar de que tiene un reconocimiento explícito en la Declaración de Derechos del Buen Pueblo de Virginia de 1776, no se estipulo dentro de la Declaración de los Derechos del Hombre y del Ciudadano de 1778. A partir de la Declaración Universal de los Derechos del Hombre de la ONU en 1948, la vida se consagra de manera solemne como un derecho, al igual que en la Convención Americana de los Derechos Humamos.

13 Según la Corte, de acuerdo con los documentos preparatorios de la Convención E/CN.4/1349 y E/ CN.4/1989/48, preexistieron tres propuestas para definir "niño": La primera proponía no incluir una definición de "niño"; la segunda definía "niño" como todo ser humano desde el nacimiento hasta la edad de los dieciocho años; la tercera definía "niño" desde el momento de la concepción. Las tres propuestas fueron rechazadas, según la Corte.

14 La doctrina constitucional no debe ser extensa por sí, pero si se cree que lo es, se debe desmitificar. Los antecedentes a esta Sentencia, si se quieren reconstruir de manera más profunda, deben incluir los salvamentos de voto de los magistrados de la Corte Constitucional Carlos Gaviria Díaz, Eduardo Cifuentes Muñoz y Alejandro Martínez, tanto en la Sentencia C-133 de 1994 como en la Sentencia C-013 de 1997, las cuales evaluaron la constitucionalidad de varias disposiciones del Decreto 100 de 1980 antiguo Código Penal. Del mismo modo, la Sentencia C-647 de 2001, que estudió la constitucionalidad de la consagración de la facultad de los jueces de prescindir de la 
que se cree, y la segunda que su influencia más evidente son las interpretaciones a los convenios y tratados internacionales en derechos humanos.

Un segundo elemento de la Sentencia tiene que ver precisamente con lo analizado por la Corte Constitucional respecto a la vida del nasciturus frente a los instrumentos internacionales de derechos humanos. Después de hacerle frente al PDESC y a la Convención del Niño, se detuvo frente a la estipulación del artículo 4.1 de la Convención Americana de Derechos Humanos que señala lo siguiente: "Toda persona tiene derecho a que se respete su vida. Este derecho estará protegido por la ley y, en general, a partir del momento de la concepción. Nadie puede ser privado de la vida arbitrariamente"

Al respecto, señaló en primer lugar que este enunciado puede tener distintas interpretaciones, las cuales dependen, por un lado, del concepto que se adopte respecto a que es "persona", y por otro lado, del concepto que se adopte respecto a la "concepción". En segundo lugar, se señala que la interpretación de este enunciado normativo está relacionado con dos momentos distintos: uno cuando se está frente al derecho al respeto a la vida y otro cuando se está frente al derecho a la protección de la vida; respecto al primero, señala que la importancia del sujetarse a la titularidad del derecho y respecto al segundo, señala como importante precisar el inicio de la protección del derecho. Esto es importante y crucial para comprender la razonabilidad de la Corte de frente a su interpretación convencional; esta primera premisa le permite justificar y concluir que el enunciado internacional incluye como "regla general" el deber estatal de protección de la vida desde la concepción, regla-deber que admite excepciones al incluir una cualificación en eventos excepcionales que la ley contemple, dado que las distintas disposiciones del derecho internacional de los derechos humanos no impone deberes de protección absoluto e incondicionales.

El tercer elemento se abstrae entonces de las consideraciones finales de la Corte. En ellas, partiendo de que se considera que se cumplió con la realización de un juicio de ponderación entre el deber de protección de la vida en gestación y los derechos fundamentales de la mujer embarazada, se concluye la siguiente tesis:

i. La prohibición total del aborto es inconstitucional.

ii. Por lo tanto, el artículo 122 del Código Penal es exequible condicionalmente.

iii. Se enumeran tres hipótesis extremas de carácter autónomo e independiente.

iv. Pueden determinarse otros casos adicionales.

v. La configuración de uno de estos casos no implica una obligación de abortar.

vi. Una mujer frente a alguna de las causales de excepción tiene derecho a decidir.

Aquí se consideró que el derecho a la vida, si se trata como un principio constitucional, no puede suponer la "negación absoluta" de otros principios o

pena, siendo de especial interés las aclaraciones de voto de los magistrados donde se exhorto en ahondar en la posibilidad de despenalizar el aborto en circunstancias extremas. A pesar de estos antecedentes, la doctrina sobre este tema no es muy extensa antes de 2006. 
derechos: los derechos fundamentales como principios de optimización, son en sí mismos relativos. Esta premisa sirvió de base para concluir que las medidas orientadas a proteger el valor de la vida del nasciturus no puede significar atentar contra los derechos de la mujer gestante entre los cuales se encuentran el derecho a gozar de modo pleno de sus derechos en materia de salud sexual y reproductiva. El proteger el valor de la vida del nasciturus hasta el extremo de penalizar toda interrupción del embarazo sería una "protección absoluta" de la vida del feto, lo cual en algunas circunstancias podría violar los derechos fundamentales de la mujer embarazada. Estos dos últimos elementos permiten establecer que si se quiere evaluar la Sentencia C-355 de 2006, se debe entrar a determinar si la ponderación realizada responde a los cánones de interpretación y argumentación establecidos por Alexy (1986).

Un cuarto elemento por considerar de la Sentencia C-355 de 2006, es el de resaltar como ya se dijo, que se evidencia en la construcción de las 80 páginas un marcado intento de interpretación convencional. Concretamente nos referimos especialmente a la Convención para la Eliminación de Todas las Formas de Discriminación contra la Mujer ${ }^{15}$, y el artículo 12 del Pacto Internacional de Derechos Económicos Sociales y Culturales (Comité de Derechos Económicos Sociales y Culturales, Observación general No. 14). La Corte indica que las recomendaciones a los Estados forman parte del bloque de constitucionalidad, y exigen que el Estado adopte las medidas orientadas a proteger la vida y la salud de la mujer en estado de gravidez, y que son criterio relevante para identificar las posibilidades fácticas y las posibilidades jurídicas en las que una mujer puede solicitar la interrupción de su embarazo. Este elemento permite identificar como criterio de evaluación de la Sentencia, las falencias en la interpretación de las convenciones, no tanto respecto a los resultados finales que buscan, sino a lo que debe ser una interpretación adecuada e integral de los instrumentos internacionales de derechos humanos.

Un quinto y último elemento en este análisis necesariamente tiene que ver con las tres situaciones fácticas que indica la Sentencia, en la que una mujer en estado de embarazo puede eventualmente interrumpir su embarazo. Al respecto, se resalta que la Sentencia a las tres posibilidades fácticas impone cargas a la vez jurídicas para que estas se surtan; una de ellas ya venía siendo trabajada (riesgo de la vida de la materna), la otra es poco común (malformación congénita grave) y la tercera tiene que ver con el delito de acceso carnal. La primera tiene un campo donde se precisa jurídicamente que ante la tensión de la vida de la materna y el nasciturus las decisiones son de quienes las soportarán en adelante, respecto a la malformación grave se incluyen recientemente los avances científicos y es el caso que abre con mayor grado el debate sobre la relación del derecho y la moral, el tercero casi que hace es una exhortación a desarrollos de política criminal.

Respecto a la última situación fáctica, es importante tener presente que se trata de un caso en el que una mujer es víctima de acceso carnal violento, y al igual que

15 Comité de la Convención para la eliminación de las formas de discriminación contra la mujer. Recomendación General No. 19, La violencia contra la mujer. Doc. N.U. A/47/28, 30 de enero, 1992, par. 7. 
todo delito impone la carga de presentar su denuncia, y al involucrar la posibilidad de concepción se debe activar a tiempo el debido protocolo médico, el cual a la fecha tiene muchos vacíos jurídicos que deben incluir las distintas hipótesis y situaciones que eventualmente podrían ocurrir, incluyendo el supuesto de víctima sin estado de gravindex. Se podría señalar aquí, que la Corte abrió una caja de pandora, esta es la única causal que realmente despenaliza una acción, pero no precisa los alcances y eventualidades, una política criminal sobre este delito debe incluir dichos estudios y obligar la ejecución de una política de salud que incluya atención oportuna, así los casos posiblemente no serían de aborto si se denuncia el delito a tiempo, dado que no prexistiría la concepción, sería un impedimento de que el óvulo llegue al espermatozoide.

Respecto a la segunda hipótesis, se introdujo una situación fáctica que para su relevancia jurídica requiere de una expedición de certificación médica de "malformación congénita grave" en quien está por nacer, tal certificación da cierta información a la materna de que la vida del nasciturus es inviable por fuera del útero, configurándose así el derecho a decidir el destino de este, sin embargo, al respecto cabe señalar tres cosas: en primera instancia la certificación del médico debe ser formal; la segunda que dicha certificación debe verificar la gravedad de la malformación, y tercero, que tal certificación incluye algún grado de probabilidad de que al nacer la vida del niño se extinguirá. A esto, se le añade que tal certificado no puede ser expedido antes de las quince semanas, ante la imposibilidad de cualquier intervención médica posterior. Por último, se diría que es la causal que realmente incluye un debate con mayor contenido moral y ético ${ }^{16}$, al limitar su ejercicio a malformaciones graves y no a niños diferentes. Sobre esta hipótesis recaerá el desarrollo final del presente trabajo.

La primera hipótesis también tiene que ver con otro registro médico, relacionado con la presencia de un riesgo en la vida de la mujer por su estado de gravidez. Al respecto, cabe señalar dos cosas: que es una situación jurídica examinada y practicada con rigor antes de esta Sentencia, y que la posibilidad jurídica nace de la certificación médica. Respecto a lo segundo, se podría comportar cierta novedad si se estipulase que la certificación médica sea formal, dado que involucra un certificado como garantía futura de una madre o un hijo inconforme con la decisión tomada.

\section{Teoría: fundamentos de las razones de la C-355-2006}

La Corte Constitucional ha incorporado teorías del derecho paulatinamente en algunos casos y en otros abruptamente (Bonilla e Iturralde, 2005), en algunos casos, por ejemplo donde se involucran cuestiones morales, se ha razonado sobre las

16 Incluso una postura del positivismo incluyente, desarrolla la tesis del valor moral contingente del derecho o de la conexión conceptual contingente, en el que en algunos casos, la moral debe ser tenida en cuenta. 
cuestiones del positivismo metodológico ${ }^{17}$ o el derecho como integridad. Este caso puede considerarse como introducción abrupta a la cultura jurídica colombiana, no es un cambio de paradigma paulatino, indudablemente es producto de una decisión de dar paso a lo que seguía, y tal razonabilidad debió confiarse a alguna teoría del derecho, ante lo álgido del debate actual, sigue siendo un tema jurídico constitucional vigente, no zanjado, y una aproximación a lo que teóricamente fue tenido en cuenta, es una aproximación obligatoria.

Como se dijo, es la Sentencia C-355 de 2006 de la Corte Constitucional la que cambia el paradigma concebido hasta entonces en relación con la prohibición de realizar cualquier interrupción del embarazo, y un estudio de su estructura proporciona cierto material para futuras evaluaciones. Así las cosas, la lectura intentó identificar los aspectos teóricos implícitos y los explícitos, desde los razonamientos y las citas expresas, teniendo en cuenta los distintos momentos en la mayoría de las casi 700 páginas de la Sentencia, las demandas presentadas por los actores, el detalle de las intervenciones ciudadanas, la intervención del defensor del pueblo, la extensa intervención del Procurador de la Nación, y finalmente, las consideraciones de la Corte, salvamentos y aclaraciones de voto.

En ese orden aparecen en la Sentencia C-355 de 2006 varios autores y teorías, sin embargo, se halló especial postura y adaptación de los postulados del Alemán Robert Alexy por varios intervinientes. Por tanto, en este escrito solo se describirá lo acogido por la Teoría de los derechos fundamentales de Robert Alexy (2007), y dejar para otro momento las tesis que se incluyeron desde la intervención de los actores como la Corporación Cisma Mujer ${ }^{18}$ respecto a los derechos de libertad positiva y libertad negativa, hasta lo expuesto en los salvamentos de voto de la Sentencia sobre Kant, Kelsen y Dworkin.

La Teoría de Robert Alexy fue expuesta en el caso preliminarmente por la demandante Roa López ${ }^{19}$. Según la reseña de la Corte Constitucional la demandante señaló que la teoría de la proporcionalidad atribuida a Robert Alexy $(1986)^{20}$ relativiza los derechos, y obliga a identificar la existencia de una tensión entre ellos, para el caso según la actora, las disposiciones penales estatales absolutas sobre el aborto y los derechos de la mujer obligan al juez constitucional arealizar el test de proporcionalidad adecuado y reconocer que con el aborto no sólo está en juego la potencia o la esperanza de vida, sino la propia vida de la mujer, su salud, su libertad o su dignidad, derecho y valores que igualmente deben ser protegidos ${ }^{21}$.

17 Véase por ejemplo la Sentencia C-486 de 1993 donde razona la perspectiva de Hart respecto a la distinción entre reglas primarias y secundarias como elementos constitutivos de un ordenamiento jurídico, o la Sentencia C-893 de 1999 en donde se hace referencia a la regla de reconocimiento.

18 Parte IV Sentencia C-355 de 2006, Intervención de la Corporación Cisma Mujer sobre "Las normas impugnadas vulneran los derechos a la libertad de conciencia y al libre desarrollo de la personalidad de las mujeres colombianas" (p. 50).

19 Parte III Sentencia C-355 de 2006, Demandante Mónica del Pilar Roa López, páginas 17 a 28.

20 Existe una primera edición traducida por Ernesto Garzón Valdés editada en el año 1993 por el Centro de Estudios Constitucionales en Madrid.

21 Parte III Sentencia C-355 de 2006, Demandante Mónica del Pilar Roa López, sobre "La proporcionalidad", página 19. 
Dice al respecto que pueden existir ciertas circunstancias excepcionales donde no es constitucionalmente exigible el deber de protección del que está por nacer.

En este sentido, desde la demanda se propone considerar los postulados de Robert Alexy (1986) específicamente respecto a su tesis de la ponderación ${ }^{22}$, previendo los factores temporal y circunstancial que ponen en tensión derechos $\mathrm{y}$, al mismo tiempo, los relativiza, en este caso, según la actora, "los derechos de la mujer frente a la obligación estatal de proteger la vida en formación”. Señala Mónica Roa que lo que se pretende no es una solicitud al juez constitucional de actuar como legislador y adicionar condiciones de tipo penal general del aborto, sino una solicitud del ejercicio de ponderación de derecho y deberes constitucionales, que en casos como graves malformaciones fetales es una violación al derecho de estar libre de tortura y tratos crueles inhumanos y degradantes donde "la proporcionalidad entre los derechos sacrificados (derecho de la mujer) y el bien protegido (vida humana en formación) es absolutamente nula" ${ }^{23}$, por tanto, considera que el artículo 122 de la Ley 599 de 2000 tal y como está contemplaba una vulneración, además de los principios fundamentales de libertad y autonomía, al principio fundamental de la proporcionalidad de la Constitución Política.

En las consideraciones de la Sentencia, la Corte ${ }^{24}$, sin citar a Alexy, propone una serie de afirmaciones axiológicas, ontológicas y metodológicas para la judiciabilidad de estos casos. En las apreciaciones la Corte libra la tensión entre "la vida como un bien constitucionalmente relevante que debe ser protegido por el Estado colombiano y el derecho a la vida misma”, y allí hace afirmaciones propias de la teoría de Alexy (1986) tales como:

El deber de protección de la vida como valor constitucional trasciende del plano meramente axiológico al normativo y se constituye como mandato constitucional en una obligación positiva o un principio de acción, según el cual

22 Alexy influenciado por Aristóteles, Immanuel Kant, Frege, Gottlob, Hans Kelsen, HLA Hart, Gustav Radbruch, Alf Ross, entre otros, a raíz de la distinción de Ronald Dworkin entre reglas y principios, propone la tesis de que los derechos fundamentales deben entenderse en algunos casos como principios para así poder concebirlos como normas sometidas a una relación estatal sirviendo así como comandos de optimización de acuerdo con las posibilidades legales y reales de la más alta medida de lo posible. Con base en esto construye una doctrina de principios que requiere un acto de equilibrio para lo cual es necesario un criterio de proporcionalidad de los derechos fundamentales.

23 Parte III Sentencia C-355 de 2006, Demandante Mónica del Pilar Roa López, sobre "Tratos Crueles, Inhumanos y Degradantes", página 22.

24 La Parte VI de la Sentencia contempla las Consideraciones y Fundamentos de la Corte destinando tan solo cien páginas de casi 700 que constituyen todo el cuerpo de la Sentencia. Dicha Parte se encuentra descrita desde la página 206 a la 302 de la Sentencia, trata inicialmente las recusaciones e impedimentos desde la 206 hasta la 218, una síntesis del objeto de estudio desde la 218 hasta la 221, el examen de cosa juzgada desde la 221 hasta 227 , posteriormente aborda ya el grueso de los temas en setenta páginas de esta Parte, empezando con los límites a la potestad de configuración del legislador en materia penal, y de manera especial los temas relacionados con los derechos fundamentales a la dignidad humana, al libre desarrollo de la personalidad, a la salud, el bloque de constitucionalidad, la razonabilidad y la proporcionalidad desde la página 227 hasta la 282, finalmente realiza el control de constitucionalidad sobre las disposiciones demandadas para lo cual hace la ponderación correspondiente de los derechos en conflicto con el deber de protección de la vida, relaciona las consideraciones finales y describe el resuelve desde la 282 hasta la 301. 
todas las autoridades del Estado, sin excepción, en la medida de sus posibilidades jurídicas y materiales, deben realizar todas las conductas relacionadas con sus funciones constitucionales y legales con el propósito de lograr las condiciones para el desarrollo efectivo de la vida humana (pp. 206-302).

Lo anterior sirvió de base para establecer varias premisas; la primera que el fundamento de la prohibición del aborto radicó en el deber de protección del Estado colombiano a la vida en gestación y no en el carácter de persona humana del nasciturus; segundo que más allá de la discusión de si el nasciturus es una persona y en esa calidad titular de derechos fundamentales, es una vida humana en gestación, y como tal el Estado colombiano tiene un claro deber de protección que se deriva; en tercer lugar que el deber de protección exalta al Estado a acciones positivas de carácter prestacional tomadas a favor de la madre gestante, pero orientadas, en definitiva, a proteger la vida de quien se encuentra en proceso de formación y de carácter legislativo para prohibir la directa intervención tanto del Estado como de terceros en la vida que se está desarrollando, concluyendo que el determinar en cada caso específico la extensión, el tipo y la modalidad de la protección a la vida del que está por nacer corresponde al legislador.

También dentro de las consideraciones cuando examina "los límites a la potestad de configuración del legislador en materia penal", específicamente respecto a la salud, la vida y la integridad de las personas, que el derecho constitucional a la salud tiene un contenido prestacional y un carácter de derecho de defensa frente a injerencias estatales o de terceros que lo amenacen o vulneren. De igual manera, esto revela la influencia teórica alemana, la faceta del derecho a la salud como derecho de defensa o libertad negativa, dentro de la cultura jurídica colombiana.

Tabla 1. La IVE en el mundo

\begin{tabular}{|cccc|}
$\begin{array}{c}\text { Circunstancias bajo las cuales se despenaliza } \\
\text { la interrupción voluntaria del embarazo }\end{array}$ & $\begin{array}{c}\mathbf{4 8} \text { países más } \\
\text { desarrollados }\end{array}$ & $\begin{array}{c}\mathbf{1 4 5} \text { países menos } \\
\text { desarrollados }\end{array}$ & $\begin{array}{c}\text { Suma de } \\
\text { los países }\end{array}$ \\
\hline Salvar la vida de la mujer & 46 & 143 & 189 \\
\hline Preservar la salud física & 42 & 80 & 122 \\
\hline Preservar la salud mental & 41 & 79 & 120 \\
\hline Violación o incesto & 39 & 44 & 83 \\
\hline Malformación fetal & 39 & 37 & 76 \\
\hline Razones socioeconómicas & 36 & 27 & 63 \\
A pedido & 31 & 21 & 52 \\
\hline
\end{tabular}

Fuente: Elaboración propia. Realizado con base en la intervención de la Procuraduría General de la Nación - Sentencia C-355 2006.

Al final de las consideraciones, la Corte cuando realiza el "examen del caso concreto", específicamente respecto a "la inexequibilidad de la prohibición total del aborto", presentó varias afirmaciones; dentro de las más relevantes se encuentra, 
en primer lugar, que "no resulta desproporcionada la protección del nasciturus mediante medidas de carácter penal", en segundo lugar que "la sanción del aborto resulta ajustada a la Constitución Política", por último, "la penalización del aborto en todas las circunstancias implica la completa preeminencia de la vida del nasciturus, y el sacrificio absoluto de todos los derechos fundamentales de la mujer embarazada, lo que sin duda resulta a todas luces inconstitucional". Desde estas premisas, se afirma que una de las características de los ordenamientos constitucionales con un alto contenido axiológico, como la Constitución colombiana de 1991, lleva a la coexistencia de distintos valores, principios y derechos constitucionales, trato que lleva a la tesis de Alexy (1986) sobre la posibilidad del trato de los derechos fundamentales como principios y la inexistencia de derechos con carácter absoluto ni preeminencia incondicional frente a los otros principios, anunciando de este modo la tesis del principio de proporcionalidad "como instrumento para resolver las colisiones entre normas con estructura de principios", sin embargo, sin citar explícitamente a Robert Alexy.

Podría decirse que la declaración de la Corte de que se encuentra ajustado a la Constitución, el artículo 122 del Código Penal condicionado a que no se incurre en delito de aborto, cuando con la voluntad de la mujer, la interrupción del embarazo se produzca por constituir peligro para la vida o la salud de la mujer certificado por un médico, por existir grave malformación del feto que haga inviable su vida certificada por un profesional de la salud, o por conducta debidamente denunciada constitutiva de acceso carnal o acto sexual sin consentimiento, abusivo, o de inseminación artificial o de transferencia de óvulo fecundado no consentidas, o de incesto, es producto de la influencia de Alexy en específico e implícitamente.

La influencia de Robert Alexy es notoria, pero no es acogida de manera íntegra, incluso en relación con su tesis sobre el principio de proporcionalidad apenas es enunciada, y puede ser confundida con apartes amplios que se hacen en la Sentencia C-355 de 2006 concerniente al deber de respeto por los principios de proporcionalidad y razonabilidad que establece tratamientos diferenciales sometidos a un juicio estricto de proporcionalidad del tipo penal, así como de la sanción penal, con un juicio de idoneidad del tipo penal. Podría ser un poco riesgoso y atrevido afirmar que si la Sentencia C-355 de 2006 ha sido sobrevalorada y que no asumió a profundidad la Teoría del Derecho contemporáneo, por lo menos en los que respecta a lo producido por el alemán. De todos modos, se evidencia como un tema muy álgido e inacabado, por lo que sería preciso seguir el paso de la descripción de los otros autores que influyeron para razonar dentro de la deliberación que se presenta actualmente ${ }^{25}$.

25 Deliberación recomendada por varios autores entre ellos Rodolfo Moreno Cruz (2009), donde relata el caso del Tribunal de Londres que autorizaba la separación de las siamesas Jodie y Mary y con ello, tácitamente, permitía la muerte de la pequeña Mary a pesar de que la madre y el padre, deseaban mantener la unión aun cuando eso acarreará la muerte de las dos, lo cual llevó a plantearse la cuestión moral de si ¿fue moralmente correcta la decisión de separar a las gemelas?, planteándose así el modelo deliberativo como alternativa para atenuar la tensión entre forma y sustancia. 


\section{CONSTRUCCIÓN DEL DERECHO FUNDAMENTAL A LA IVE ${ }^{26}$}

\section{Primer antecedente pos C-355}

Posterior a la Sentencia C-355 de 2006, lo primero que surge es un intento por parte del Poder Ejecutivo de reglamentar la prestación de unos servicios de salud sexual y reproductiva. El ejecutivo a través del Decreto 444 de 2006 aborda la reglamentación nominando como un servicio de Interrupción Voluntaria del Embarazo no constitutiva del delito de aborto, le da la categoría de garantía de acceso real y atención oportuna, y lo nomina "Servicio IVE". El Decreto 444 de 2006 de la Presidencia de la República ${ }^{27}$ fue suspendido provisionalmente mediante auto de 15 de octubre de 2008 por la Sala de lo Contencioso Administrativo, Sección Primera, del Consejo de Estado (Dra. María Claudia Rojas Lasso, expediente 200800256-00). El fundamento de la decisión radica en extralimitación del Ejecutivo en ejercicio de la facultad reglamentaria y por invadir el terreno de las leyes estatutarias al reglamentar el ejercicio de la objeción de conciencia.

\section{7: derecho al servicio IVE}

El Decreto 444 de 2006, antes de su nulidad, alcanzó a ser una fuente válida para la Corte Constitucional. En la Sentencia T-988 de 2007 del Magistrado Ponente Humberto Sierra Porto frente a un caso de acceso carnal violento no consentido en una joven con discapacidad por un cuadro de parálisis cerebral y retardo sicomotor severo e hipotiroidismo que le producen limitaciones físicas, psíquicas y sensoriales y la reducen a estar inmovilizada en silla de ruedas. Se dictaminó que la IPS impuso a la joven una carga desproporcionada, arbitraria e injustificada, bajo entero desconocimiento de sus derechos constitucionales fundamentales.

Tabla 2. Ficha de la línea jurisprudencial

Objetivo y límites de la línea: reconstruir la construcción del derecho fundamental a la interrupción voluntaria del embarazo, realizado en sede de la Corte Constitucional colombiana, teniendo como enlace temático la influencia e interpretación de las fuentes del derecho internacional de los derechos humanos, para evaluar en otro momento la adecuada vinculación de los instrumentos, órdenes, informes, observaciones, documentos técnicos y demás fuentes de los sistemas de los derechos humanos.

26 La construcción de un derecho fundamental está presente en la doctrina constitucional. Una reconstrucción del derecho fundamental al territorio ancestral, ver en: Fernando Guerrero (2010).

27 Que pretendía reglamentar la prestación de unos servicios de salud sexual y reproductiva, fue expedido por el entonces presidente, Álvaro Uribe Vélez. El Decreto señalaba expresamente que la disponibilidad del servicio IVE "no constitutiva del delito de aborto", estará disponible en todos los grados de complejidad que requiera la gestante, en las instituciones prestadoras habilitadas para ello, de acuerdo con las reglas de referencia y contrarreferencia, y demás previsiones contenidas en el presente decreto". 


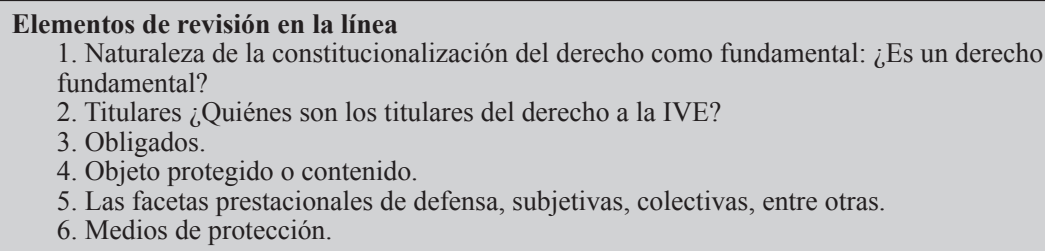

Sentencia que permite reconstruir la línea (Sentencia arquimédica y sentencia hito). Sentencia de constitucionalidad: Sentencia C-355 de 2006 (Sentencia que introduce un elemento nuevo al derecho). Criterio de selección: Sentencia de constitucionalidad.

Sentencia de tutela: Sentencia T-627 de 2012 (Sentencia punto de partida para reconstruir la línea). Criterio de selección: Sentencia más reciente y más polémica en relación con el derecho como derecho fundamental.

\section{Sentencias y decisiones de la Corte derivadas preliminarmente de la Sentencia arquimédica}

Sentencia T-627 DE 2012: tutela de más de 1200 mujeres; se trató como solicitud de protección del derecho a la información de los derechos sexuales y reproductivos del derecho a la IVE, conforme a la Sentencia T-585 de 2010.

\begin{tabular}{|l|l|}
\hline Sentencia T-388 de 2009: & $\begin{array}{l}\text { Orden de promoción de los derechos derivados de } \\
\text { la Sentencia C-355 de } \\
2006 .\end{array}$ \\
\hline Sentencias T-585 de 2010: & $\begin{array}{l}\text { Indica que la Sentencia C-355 de 2006 señala los } \\
\text { casos despenalizados por la Corte, que comportan } \\
\text { un derecho de carácter fundamental perteneciente } \\
\text { a la categoría de los derechos reproductivos. }\end{array}$ \\
\hline Auto 038 de 2012: & $\begin{array}{l}\text { Desestimó la nulidad impetrada contra la } \\
\text { Sentencia T-585 de 2010 por parte del Procurador } \\
\text { General. }\end{array}$ \\
\hline Sentencia T-841 de 2011: & \begin{tabular}{l} 
Reitera lo indicado en la sentencia T-582 2010. \\
\hline
\end{tabular} \\
\hline
\end{tabular}

La Corte dado que al momento de fallar constató que el embarazo ya no existía y tampoco se había presentado el parto, decidió advertir a la E.P.S. demandada que en adelante, la IVE de una mujer discapacitada víctima de acceso carnal violento no consentido o abusivo, debía "abstenerse de elevar obstáculos de orden formal." Precisó, del mismo modo, que bajo tales circunstancias la solicitud de IVE podía efectuarla cualquiera de los padres de la mujer que se halla en esta situación u otra persona que actúe en su nombre sin requisitos formales adicionales al denuncio penal por acceso carnal violento o no consentido o abusivo.

En esta Sentencia se adoptaron las regulaciones contenidas en el Decreto 444 de 2006 antes mencionado, se consideraron aplicables al caso, y armónicas con lo establecido por la Constitución Nacional y con lo consignado en la ratio decidendi contenida en la Sentencia C-355 de 2006 (sin embargo, se intuía lo cuestionable de 
su validez). Esta Sentencia es entonces, quien, por tanto, por primera vez lo nomina como Servicio IVE dándole el mismo trato jurídico de servicio del Decreto 444 de 2006.

Por otra parte, la mencionada Sentencia se refirió a la protección reforzada derivada del derecho internacional de los derechos humanos, cuando se trata de mujeres en estado de embarazo de especialísima protección, como las mujeres discapacitadas que han sido objeto de acceso carnal violento, en este contexto vinculo como fuentes a la "Convención Interamericana para la Eliminación de Todas las Formas de Discriminación contra las Personas Discapacitadas", así como las "Normas Uniformes sobre la Igualdad de Oportunidades de Personas con Discapacidad", al igual que la "Convención Interamericana como Fuente para la Definición de Persona con Discapacidad" 28 . De igual manera, se citó la Observación General No. 5 sobre los derechos de las personas con discapacidad emitida por el Comité de Derechos Económicos, Sociales y Culturales que estableció la obligación del Estado de proteger a los discapacitados y de promover sus derechos mediante programas y leyes generales, así como por medio de programas y normatividades de finalidad específica.

\section{8: derecho al procedimiento legal IVE del SGSSS}

Ya en la Sentencia T-209 de 2008 de la Magistrada Ponente doctora Clara Inés Vargas Hernández, se amplía el trato de Servicio Público IVE a "Procedimiento Legal IVE del Sistema General de Seguridad Social en Salud" precisando que puede ser solicitado por cualquier persona en favor de la mujer en estado de gravidez, cuando esta es incapaz de realizarlo voluntariamente (en este caso se trató la validez de una solicitud de interrupción de embarazo por acceso carnal violento por parte de la madre de una niña menor de 14 años), igualmente que dicha solicitud no requiere autorización o consenso de varios médicos, consentimiento del marido, padres u otros familiares de la gestante, o de jueces o tribunales, es una facultad personal (del Comité para la Eliminación de todas las Formas de Discriminación contra la Mujer de la ONU, 1994)29. Como "Procedimiento Legal IVE del SGSSS" la Corte enumera tres de sus características:

28 El Artículo 1.1. de la Convención Discapacidad señala que el término "discapacidad" significa una deficiencia física, mental o sensorial, ya sea de naturaleza permanente o temporal, que limita la capacidad de ejercer una o más actividades esenciales de la vida diaria, que puede ser causada o agravada por el entorno económico y social". Esto fue la fuente normativa para calificar la existencia de una discapacidad de la joven víctima de acceso carnal a la que refiere la Sentencia T-988 de 2007.

29 Donde se reconoce que este tipo de decisiones son personales, pues "la decisión [de la mujer] de tener hijos...no debe...estar limitada por el cónyuge, el padre, el compañero o el gobierno...” (párr. 22). En el mismo sentido, se refiere el Comité de Derechos Humanos de la ONU (2000): “... cuando se obliga al marido a dar su autorización para decidir sobre la esterilización de la mujer, o cuando se establecen requisitos generales para la esterilización de la mujer, como por ejemplo, tener cierto número de hijos o cierta edad, o cuando es obligatorio que los médicos y otros funcionarios de salud informen sobre los casos de mujeres que se someten a abortos [se vulnera el derecho a la autodeterminación" (párr. 20). 
- Es un procedimiento oportuno, por lo cual los profesionales de la salud del Sistema General de Seguridad Social en Salud deberán proceder a realizar el procedimiento IVE dentro de los cinco (5) días siguientes a la solicitud, de conformidad con la Resolución 004905 de 2006, proferida por el Ministerio de la Protección Social.

- Es un procedimiento que amerita una atención integral y de calidad.

- El procedimiento es técnico-administrativo, regido por lo expedido por el Ministerio de la Protección Social, normas que serán de obligatorio cumplimiento, y mientras estas se expiden, los prestadores están obligados al cumplimento de las normas del Decreto 4444 de 2006 que tienen como referente la guía "Aborto sin riesgo: Guía técnica y de políticas para sistemas de salud" de la Organización Mundial de la Salud (2003).

En relación con los documentos internacionales que influyeron en la Sentencia T-209 de 2008, especialmente en su argumento de que es un procedimiento médico en titularidad de la mujer gestante, se resalta la "Guía Técnica de Políticas para Sistemas de Salud: Aborto sin Riesgos", de la Organización Mundial de la Salud de 2003 que establece que es un procedimiento al que tiene derecho la mujer que involucra sus derechos sexuales y reproductivos; la Conferencia Internacional sobre Población y Desarrollo (ICPD) desarrollada en El Cairo en 1994 donde se reconoció que el aborto inseguro es una de las mayores preocupaciones de la salud pública y se garantizó el compromiso de disminuir la necesidad de un aborto a través de la expansión y mejoramiento de los servicios de planificación familiar, mientras que, al mismo tiempo, se reconoció que en los casos en que no estén contra le ley, el aborto debe ser sin riesgos. Igualmente, se enunció los Tribunales Internacionales de Ética Médica, como órganos competentes para evaluar la procedencia de una presentación de objeción de conciencia para practicar una IVE.

\section{Dilación injustificada de la autorización para un procedimiento legal IVE}

En la Sentencia T-946 de 2008, la Corte señala que la negativa o la dilación injustificada en la autorización del "Procedimiento de IVE" vulnera los derechos a la integridad, a la libertad, a la dignidad, entre otros, de las mujeres que no son remitidas de forma oportuna y adecuada a un centro de servicios médicos en donde los profesionales de la salud les aseguren la interrupción del embarazo. El Magistrado Ponente doctor Jaime Córdoba Triviño adoptó esta postura de un caso de una acción de tutela interpuesta por la madre de una niña con cuadro clínico de síndrome de Pradder Willy o Daown, el cual es limitante en gran porcentaje de su capacidad cognoscitiva, la cual fue interpuesta cuando la madre se dio cuenta que su hija estaba embarazada con 18 semanas de gestación, sin duda por acceso carnal abusivo sin consentimiento en menor en estado de indefensión e incapaz de resistir, con posibilidades de malformaciones del feto por la transmisión genética y el consumo prolongado de la droga denominada Epanime. 
En esta Sentencia ocurrió algo particular respecto a la incidencia de los instrumentos internacionales, ya que la Corte ordenó comunicar al Tribunal Nacional de Ética Médica lo resuelto para la correspondiente investigación y posterior sanción. Igualmente, se registra un salvamento de voto de Rodrigo Escobar Gil en relación a si se vulneraron los derechos de "una mujer cuya gestación es el resultado de un acceso carnal no consentido" y la aclaración de voto de Mauricio González Cuervo en relación a la advertencia de la falta de regulación sobre la materia.

\section{Titular de la decisión de solicitud del procedimiento legal IVE}

La Sentencia T-009 de 2009 fue radical en afirmar que solamente la madre gestante tiene la decisión para continuar o interrumpir un embarazo cuando este representa riesgo para su vida o su salud y un médico así lo ha certificado, acentuando que es una decisión de alta importancia donde será la mujer quien deba soportar las consecuencias que se deriven de dicha decisión. El Magistrado Ponente doctor Manuel José Cepeda resaltó que la Sentencia T-881 de 2002 (M.P. Eduardo Montealegre Lynett) estableció que la dignidad humana cuenta con tres dimensiones ${ }^{30}$ que no pueden ser vulneradas; en consecuencia, las personas no pueden ser un objeto sobre el cual otros toman decisiones trascendentales para el proyecto de vida de la persona. Igualmente, se ordenó a la EPS que en un plazo de un mes de cabal cumplimiento a las obligaciones contenidas en la Circular 0031 de 2007 e informe al Ministerio de Protección Social las instituciones dentro de su red habilitada para prestar servicios de gineco-obstetricia de baja, mediana y alta complejidad, que cuentan con profesionales dispuestos a proveer los servicios de IVE. Aquí, Rodrigo Escobar Gil, salvó su voto y señaló que el estudio de caso se apartó de la realidad y el problema jurídico planteado por la accionante.

30 La mencionada Sentencia las describe así: “(i) La dignidad humana entendida como autonomía o como posibilidad de diseñar un plan vital y de determinarse según sus características (vivir como quiera). (ii) La dignidad humana entendida como ciertas condiciones materiales concretas de existencia (vivir bien). Y (iii) la dignidad humana entendida como intangibilidad de los bienes no patrimoniales, integridad física e integridad moral (vivir sin humillaciones)". También cita entre otras la Sentencia T-532 de 1992 donde la Corte señaló la estrecha relación entre la libertad individual y la dignidad humana, la Sentencia C-542 de 1993 donde la Corte recurrió al imperativo categórico kantiano para reforzar la idea según la cual no pueden superponerse los intereses generales a los derechos fundamentales, la Sentencia C-221 de 1994 done la Corte consideró que la dignidad y la libertad personal se concreta en la posibilidad de elegir el propio destino, la Sentencia T-477 de 1995 donde la Corte estudio el caso de la readecuación de sexo de un menor, la sentencia T-472 de 1996 donde la Corte estableció que las personas jurídicas no son titulares de los derechos fundamentales a la honra y al buen nombre debido a que los mismos constituyen una derivación directa del principio de dignidad humana y la Sentencia C-239 de 1997 donde la Corte creó una causal de justificación o eximente de responsabilidad en el caso del homicidio pietístico. 


\section{Obligación de las autoridades estatales de promoción del servicio al procedimiento IVE: T-388 de 2009}

La Sentencia T-388 de 2009 del Magistrado Ponente Humberto Sierra Porto, examina el Decreto 444 de 2006 antes de ser suspendido provisionalmente por el Consejo de Estado, describiendo los mandatos que se derivan del contenido de la Sentencia C-355 de 2006 de la Corte Constitucional en materia de derechos sexuales y reproductivos para las mujeres, las consecuencias prácticas surgen para las EPS, las IPS y el personal médico que en ellas labora en cumplimiento de la sentencia C-355 de 2006, y resolvió si los funcionarios judiciales pueden declararse objetores de conciencia en desarrollo de sus funciones. El caso tratado en esta ocasión por la Corte Constitucional fue una IVE por embarazo de feto único, polimalformado, con probable displasia ósea.

Esta Sentencia es muy importante porque ordena al Ministerio de la Protección Social así como al Ministerio de Educación Nacional, a la Procuraduría General de la Nación y a la Defensoría del Pueblo, diseñar y poner en movimiento campañas masivas de promoción de los derechos sexuales y reproductivos que contribuyan a asegurar a las mujeres en todo el territorio nacional el libre y efectivo ejercicio de estos derechos y, en tal sentido, el conocimiento de lo dispuesto en la Sentencia C-355 de 2006; por otra parte, se ordenó a la Superintendencia Nacional de Salud adoptar medidas indispensables, con el fin de que las EPS e IPS cuenten con las personas profesionales de la medicina, así como el personal idóneo y suficiente para atender y garantizar el servicio de interrupción voluntaria del embarazo bajo los supuestos previstos en la Sentencia C-355 de 2006. De esta manera, la Corte interpreta "la obligación de las autoridades estatales respecto a la promoción de la IVE", desencadenando una tensión principalmente con la Procuraduría, que interpreta esta Sentencia como una orden para promover el aborto. El razonamiento en esta oportunidad de la Corte lo resumo así:

(i) La mujer bajo las hipótesis de la Sentencia C-355 de 2006 son las titulares del derecho a decidir libremente respecto de la IVE.

(ii) Todas las mujeres para poder decidir deben poder contar con la información suficiente, amplia y adecuada respecto a la IVE, lo cual incluye el derecho a estar plenamente enteradas respecto de lo dispuesto en la Sentencia C-355 de 2006.

(iii) Ante la evidencia generalizada del desconocimiento de la Sentencia C-355 de 2006 por parte de los sujetos involucrados en un procedimiento de IVE, es prioritario campañas masivas de las autoridades competentes para tal fin y el que se adopten por las entidades encargadas las medidas necesarias para atender y garantizar este servicio médico. 


\section{IVE derecho fundamental: T-585 de 2010}

La norma que bautiza a la IVE como derecho fundamental por primera vez, es la Sentencia T-585 de $2010^{31}$ con Magistrado Ponente Humberto Sierra Porto. La Corte concluyó que las prerrogativas que conceden los derechos reproductivos, incluida la IVE, son parte de los derechos fundamentales reconocidos en la Constitución de 1991, ya que dentro del contenido del derecho a la autodeterminación reproductiva, se expresa el derecho de las mujeres a la IVE cuando se encuentran en las hipótesis despenalizadas, y a su vez, estos están implícitos en los derechos fundamentales a la vida digna, a la igualdad, al libre desarrollo de la personalidad, a la información, a la salud y a la educación, entre otros, y que en razón a esto nacen las correlativas obligaciones de respeto y garantía en cabeza del Estado y los promotores y prestadores del servicio de salud. La referida Sentencia señaló:

Resulta innegable que, a partir de la Sentencia C-355 de 2006 surgió en Colombia un verdadero derecho a la interrupción voluntaria del embarazo en cabeza de las mujeres que se encuentran incursas en las tres hipótesis despenalizadas. En efecto, como se indicó en esta sentencia la Corte concluyó que la protección de los derechos fundamentales de la mujer a la dignidad humana, al libre desarrollo de la personalidad, a la vida y a la salud física y mental -contenidos en la Constitución de 1991 y en el bloque de constitucionalidad- implican reconocerle la autonomía para decidir libremente si interrumpir o continuar la gestación en las tres precisas circunstancias ya señaladas, de modo tal que la sanción penal resultaba desproporcionada. En otras palabras, del contenido de los derechos fundamentales mencionados la Corte derivó el derecho a la IVE de las mujeres gestantes que se encuentran en los eventos antes indicados.

Así las cosas, esta Sentencia lo nomina “derecho fundamental a la IVE”, influido por un caso de amenaza de la vida de una joven madre cabeza de familia con un embarazo diagnosticado como de alto riesgo ${ }^{32}$. Su razonamiento puede resumirse así:

31 Según el folio 18, cuaderno 1, citado en esta Sentencia en su página 7 del formato web, la accionante al ser preguntada por su estado de salud respondió que "tengo 11 semanas de embarazo, (...) mi estado de salud es malo, me siento enferma, vomito todo el tiempo y en ocasiones con sangrado, dolores de cabeza intensos, escucho pitos, veo lucecitas, dolor bajito, ardor y dolor en el estómago, los médicos dicen que es por el vómito y lo que más me preocupa es que pierdo un kilo semanal", agregó que "me siento decaída, enferma, anímicamente me siento triste y desesperada, ya que nadie me da solución a lo que tengo ni puedo trabajar para mantener a mi menor hija", así mismo indicó que "he tenido dos amenazas de aborto, el 4 y 13 de noviembre del presente año".

32 Según el folio 38, cuaderno 1, citado en esta Sentencia en su página 8 del formato web, el juzgado de primera instancia de esta acción de tutela, contó con una valoración practicada por el ginecólogo obstetra Rodrigo Reyes, quien conceptuó: "Paciente con alto riesgo de preclampsia pero que en el momento no tiene preclampsia, ni enfermedad orgánica que ponga en peligro inminente su vida como lo consagra la ley para interrumpir el embarazo. Sin embargo, con una carga emocional que amerita concepto de psicólogo para determinar aptitud para continuar gestación si psicólogo [sic] emite concepto de paciente no apta psicológicamente, estaremos atentos para interrumpir el embarazo o cuando existe indicación médica". 
- Ninguno de los valores, principios o derechos constitucionales fundamentales se garantiza en el ordenamiento jurídico constitucional colombiano de manera absoluta, pues estos deben poder dar lugar a la ponderación frente a otros valores, principios y derechos cuya protección también resulta relevante desde el punto de vista constitucional.

- El ordenamiento constitucional colombiano le confiere protección al valor de la vida y al derecho a la vida, pero esta protección no tiene igual extensión.

- Existe una protección general de la vida que engloba el valor de la vida del nasciturus. La ley puede diseñar los mecanismos para protegerla de la manera más óptima posible. El legislador puede acudir al derecho penal para esos efectos.

- La penalización debe surtirse bajo las fronteras que traza la Constitución misma, que incluye lo dispuesto por el artículo 93 superior sobre las garantías consignadas en un conjunto de convenios internacionales sobre derechos humanos aprobados por Colombia.

- Ninguna medida de penalización puede infringir los derechos de la mujer gestante a la dignidad, a la libertad en general, al libre desarrollo de su personalidad, que incluye así mismo la salud sexual y reproductiva.

- Un amparo absoluto al valor de la vida del nasciturus equivale a una intromisión estatal desmesurada apartado del principio de proporcionalidad desarrollado por la jurisprudencia constitucional y las garantías de protección del ámbito internacional de los derechos humanos.

La Sentencia en el caso examinado, al concretar el "derecho fundamental a la IVE" resalta que este comporta una obligación prestacional estatal que debe garantizar condiciones de calidad, oportunidad y seguridad, lo cual incluye una importante faceta de "protocolos de diagnóstico diligentes" que permitan advertir la existencia de una de las hipótesis de la Sentencia C-355 de 2006 y el consiguiente trámite, si es el caso, de producir de inmediato la certificación médica requerida.

\section{Derecho fundamental a la IVE como integrante de los derechos reproductivos}

Una penúltima Sentencia es la T-841 del 2011 de Humberto Sierra Porto. En esta sentencia se examinó el "derecho fundamental de reserva de las mujeres que solicitan la IVE, el derecho fundamental de las mujeres a la IVE como derecho reproductivo cuando existe peligro para la vida o la salud física o mental de la gestante, el derecho fundamental procedimental a la IVE", producto de un caso de una tutela interpuesta por la madre de una niña de doce años con diecinueve semanas de gestación producto de una relación sexual sostenida con su novio menor de edad de dieciséis años, con intento de suicidio de la menor producto de una "reacción depresivoansiosa" con "síntomas depresivos y angustia severa" que confiere su edad y su nivel socioeconómico, con riesgo de sufrir detrimento de su salud mental, social y física como resultado de asumir la maternidad a tan temprana edad. 
En ella, se sigue el trato de "Derecho Fundamental de las mujeres a la IVE como Derecho Reproductivo" en los casos despenalizados, y cita la Sentencia T-588 de 2010 como la que lo aclara. En este caso, se examinó la relación con el derecho a la intimidad personal, donde lo íntimo puede exigirse que no sea divulgado o publicado y así sustraerse de cualquier tipo de opinión pública respecto a la decisión de no llevar a término un embarazo por parte de una mujer.

La Corte resaltó el "derecho fundamental prestacional procedimental al diagnóstico" (Sentencias T-452 de 2010, T-717 de 2009, T-055 de 2009, T-274 de 2009, T-050 de 2009, T-760 de 2008, T-398 de 2008, T-795 de 2008, T-253 de 2008, T-1180 de 2008, T-881 de 2008, T-570 de 2008, T-083 de 2008, T-1177 de 2008 y T-324 de 2008), integrante del derecho fundamental a la salud (en este caso a la salud reproductiva) y adscrito al derecho a la dignidad humana, toda vez que una actuación inoportuna obliga al paciente a soportar inclemencias siendo éstas evitables con la puntual iniciación del tratamiento médico posterior a su diagnóstico, siendo características de este el ser oportuno, completo y de calidad. Revisando la línea jurisprudencial sobre el denominado derecho al diagnóstico halla las coincidencias con la faceta de diagnóstico del derecho fundamental a la IVE. Del mismo modo, en él se protegió la intimidad de los actores ordenando a todas las autoridades involucradas guardar estricta reserva sobre la identidad de la gestante so pena de las sanciones legales que correspondan por el desacato a esa orden judicial.

\section{Derecho a la información de los derechos sexuales y reproductivos del derecho a la IVE: T-627 de 2012}

Por último, la Sentencia T-627 de 2012 de la Corte Constitucional del Magistrado Ponente Humberto Sierra Porto resolvió una tutela presentada por más de 1280 mujeres, la cual a pesar de presentar vacíos respecto al contenido de su petición, la Corte asumió el caso, interpretando extensivamente la acción de tutela presentada. Esta Sentencia presentó mayor controversia que las que las antecedieron y que en conjunto representan la construcción doctrinal de la Corte, por lo que enunciaré con más detalle, algunos de sus aspectos más relevantes. En primer lugar, resaltaré lo anteriormente señalado, y daré paso a describir las razones de los accionantes, de la procuraduría y de la Corte.

\section{a. Humberto Sierra Porto protagonista de la construcción jurisprudencial}

En primer lugar, se puede realizar la siguiente afirmación: La Corte Constitucional no asumió el caso de las 1280 mujeres, conforme fue expuesto en la acción de tutela, en su lugar interpretó que se trataba de una solicitud de amparo de protección al derecho fundamental a la información de los derechos sexuales y reproductivos del 
derecho fundamental a la IVE, conforme a la Sentencia T-585 de $2010^{33}$, reiterada por la sentencia T-841 de 2011, Sentencias que también tenían como Magistrado Ponente a Humberto Sierra Porto. La anterior afirmación se basa en la misma consideración de la Corte, que indica los motivos por que interpreta extensivamente el amparo solicitado.

\section{b. Razones de las 1280 accionantes}

Primera razón: la Procuraduría General de la Nación, al interpretar la Sentencia T-388 de 2009, emitió de manera continua y sistemática una serie de pronunciamientos con información inexacta o tergiversada, relacionada con lo señalado en la Sentencia sobre los derechos reproductivos de las mujeres entre ellos el derecho fundamental a la IVE, llegando a emitir finalmente un comunicado de prensa de fecha 21 de octubre de 2009, donde afirma que la Corte Constitucional había ordenado implementar campañas masivas de promoción del aborto", cuando la Sentencia, según las peticionarias, ordenó promover campañas masivas de promoción del aborto en los casos señalados en la Sentencia C-355.

Segunda razón: la Organización Mundial de la Salud, a través de la Nota Descriptiva No. 244 "Levonorgestrel para anticoncepción de emergencia" de octubre de 2005, demuestra que las píldoras anticonceptivas de emergencia que contienen Levonorgestrel solo previenen la ovulación y "no producen efectos detectables sobre el revestimiento interno del útero", cuando son administradas después de la ovulación, y según las peticionarias, asegura que las píldoras no son eficaces una vez que el proceso de implantación en el útero ha iniciado, por tanto, no podrían provocar un aborto. Igualmente afirma que la Procuraduría no aporta prueba o información científica proveniente de fuente con autoridad sobre la materia, para omitir la promoción de su uso y desvirtuar este criterio de autoridad internacional.

Tercera razón: la Sentencia T-585 de 2010 la Corte Constitucional indicó que resulta innegable que a partir de la Sentencia C-355 de 2006 surgió en Colombia un verdadero derecho a la interrupción voluntaria del embarazo en cabeza de las mujeres que se encuentran incursas en las tres hipótesis despenalizadas, el cual según la Relatoría Especial para los Derechos de la Mujer de la Comisión Interamericana de Derechos Humanos del 13 de julio de 2011 no es contrario a la Convención Americana que protege el derecho a la vida desde la concepción.

33 La Corte destacó que en el Auto 038 de 2012 la Sala Plena de esta Corte desestimó la nulidad impetrada contra la Sentencia T-585 de 2010 por parte del Procurador General, entre otras cosas, porque "la Sala Octava no efectuó ningún cambio de jurisprudencia respecto de lo decidido en la Sentencia C-355 de 2006 al indicar en la Sentencia T-585 de 2010 que, en los casos despenalizados por esta Corte, la IVE es un derecho de carácter fundamental perteneciente a la categoría de los derechos reproductivos". 
Cuarta razón: la Sala Especializada de Medicamentos y Productos Biológicos de la Comisión Revisora del INVIMA en el Acta No. 20 de 2007 determinó que el Misoprostol podía ser empleado para circunstancias de IVE (lo cual es cierto, pero sería efectivo solo si es anticonceptivo y, en ese caso, solo sería útil para la causal de acceso carnal violento y antes de producirse la fertilización del óvulo por el espermatozoide, ya que es infértil después de la fecundación por ser de naturaleza anti-conceptiva, antes de la concepción), basándose en un documento de la OMS del 2010 titulado "Aclaración sobre la postura de la OMS respecto del uso del Misoprostol en la comunidad para reducir la mortalidad materna", que describe también los riesgos del Misoprostol en estados de embarazo.

Quinta razón: las 1280 accionantes, en las que se encontraba Mónica Roa, protagonista también en la Sentencia C-355 de 2006, basaron su tesis de manera extensa en pronunciamientos de varios organismos internacionales autorizados para interpretar algunos tratados sobre derechos humanos ratificados por Colombia como la Observación General No. 24 del Comité de la Convención para la "Eliminación de Todas las Formas de Discriminación contra la Mujer" sobre el deber de los Estados de asegurar el acceso de las mujeres a la información, especialmente sobre su salud sexual y reproductiva; en el mismo sentido, los pronunciamientos del Comité de Derechos del Niño sobre la importancia del acceso a la información a los niños, sobre todo en lo relativo a su salud sexual y reproductiva, la Observación No. 14 del Comité de Pacto de Derechos Económicos, Sociales y Culturales sobre la dependencia de la garantía del derecho al más alto nivel de salud física y mental al acceso a la educación y a la información especialmente en lo referente a la salud sexual y reproductiva, la Relatoría para los Derechos de la Mujer de la Comisión Interamericana de Derechos Humanos sobre las garantías en educación e información a las usuarias en relación con los servicios de salud incluyendo la salud reproductiva y los documentos de la Organización Mundial de la Salud.

\section{c. Razones de la Procuraduría General de la Nación: El deseo como fuente}

Para la Procuraduría la orden de la Sentencia T-388 de 2009 es objeto de nulidad, puesto que el aborto sigue siendo un delito después de la Sentencia C-355 de 2006, y esta solo contempló tres excepciones, y además NO le confirió la naturaleza de derecho a la interrupción del embarazo (lo cual es cierto, ya que es hasta la Sentencia analizada que se nomina como tal). Del mismo modo, se consideraba que las órdenes contenidas en la Sentencia T-388 de 2009 de promover las causales legales para el aborto eran inaplicables hasta tanto no se decidiera la solicitud de nulidad presentada por la Procuraduría, esto respecto a la orden de implementar una cátedra del aborto en colegios (la Procuraduría asume la Sentencia como una fuente formal objeto de solicitud de suspensión por parte del Consejo de Estado). 
Por otra parte, para la Procuraduría acatar la orden promoviendo el uso del Levonorgestrel puede ser el fomentar una forma de aborto ilegal, ya que puede el Levonorgestrel impedir que un óvulo "ya fecundado" se anide o implante en el útero. Para la Procuraduría en esta etapa ya hay embarazo y el mecanismo de acción del Levonorgestrel actuaría como método abortivo, pues provocaría la muerte del óvulo ya fecundado (que puede durar hasta 7 días en las trompas de Falopio antes de llegar al útero) fuera de las causales que provocan el servicio de IVE y que producen obligaciones de prestación de servicios de interrupción del embarazo.

De otro lado, la Procuraduría manifestó que "los pronunciamientos de la Organización Mundial de la Salud a pesar de ser conceptos del alta envergadura para el sector de la salud no constituyen una normatividad vinculante para nuestro país, toda vez que la ejecución y el seguimiento de sus recomendaciones es potestativo de cada uno de los países que integran la Organización de las Naciones Unidas", infiriéndose de esto que no se debe deliberar quién es el máximo intérprete de los documentos de la OMS, sino que se debe apropiar una postura médica interna respecto a los procedimientos de interrupción del embarazo. Sin embargo, la Procuraduría acepta lo consagrado en el Informe Técnico 461 de la Organización Mundial de la Salud, emitido en 1970 que define el aborto como la interrupción del embarazo antes de que el feto sea viable y que precisa que la implantación del óvulo fecundado constituiría o no un aborto según la definición que se adopte de la concepción y del embarazo.

\section{d. Razones de la Corte Constitucional}

La Corte realizó una reconstrucción de la argumentación empleada para el surgimiento del derecho a la IVE en cabeza de las mujeres que se encuentran incursas en las hipótesis despenalizadas describiendo principalmente lo siguiente:

(i) La importancia del bloque de constitucionalidad.

(ii) La categoría de derechos humanos de los derechos reproductivos.

(iii) La naturaleza fundamental del derecho a la autodeterminación reproductiva.

(iv) El surgimiento de un conjunto de obligaciones de respeto y de garantía en cabeza del Estado y de los prestadores y promotores del servicio público de salud.

(v) Derecho a un procedimiento en condiciones de oportunidad, calidad y seguridad.

(vi) Derecho de elección de las mujeres colocadas en los supuestos determinados.

(vii) Derecho a la información suficiente, amplia y adecuada sobre sus derechos sexuales y reproductivos que incluye lo dispuesto en la sentencia C-355 de 2006. 
(viii) Derecho de las mujeres a la intimidad y a la dignidad.

(ix) El acceso efectivo al servicio de IVE en condiciones de calidad y de salubridad.

(x) La obligación de garantía de la faceta de diagnóstico del derecho fundamental a la IVE.

Principalmente ${ }^{34}$ determinó que era un caso del "derecho fundamental a la información en materia reproductiva en poder del Estado", siendo el derecho a la información un componente de los derechos sexuales y reproductivos (CADH, art. 13) $)^{35}$. La principal fuente de la Corte para fundamentar la relevancia de este derecho fue la Relatoría Especial para la Libertad de Expresión de la CIDH, la Sentencia Interamericana Caso Perozo y otros contra Venezuela y Ríos y otros contra Venezuela, la Convención para la Eliminación de Todas las Formas de Discriminación contra la Mujer (CEDAW, art. 16, e) ${ }^{36}$, la Recomendación General № 21 del Comité de la CEDAW de 1994, la Observación No. 28 del Comité de Derechos Humanos de marzo del 2000, el Pacto Internacional de los Derechos Económicos, Sociales y Culturales

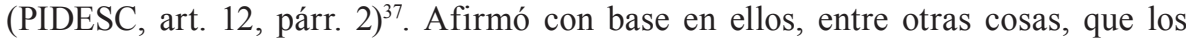
derechos reproductivos reconocen y protegen (i) la autodeterminación reproductiva y (ii) el acceso a servicios de salud reproductiva; que el derecho a la salud comprende el derecho a la salud genésica cuyo concepto comprende el derecho del hombre y la mujer a estar informados y tener acceso a métodos de planificación familiar.

\section{REFLEXIÓN DESDE LA DIMENSIÓN ÉTICA DEL DERECHO A NACER: HACIA UNA LEY PARA EL MÁS DÉBIL}

Al parecer, la sociedad ya decidió su postura frente a la tensión de los derechos reproductivos de las mujeres frente a la ley del más débil o el derecho inexistente del nasciturus. Son varios los problemas que se derivan de la construcción constitucional, los cuales pueden ser abordados, desde el derecho y entre otras perspectivas jurídicas, como una perplejidad cognitiva, descriptiva o axiológica. Sin embargo, una descripción del problema que inquieta el presente escrito, prefiere optar por

34 Humberto Sierra Porto no solo reconstruye el derecho fundamental, sino que amplía su contenido. En ese sentido, se incluye no solo la información sobre anticoncepción sino, en general, sobre la salud reproductiva, con fundamento, una vez más, en tratados internacionales sobre derechos humanos que hacen parte del bloque de constitucionalidad, tal como han sido interpretados por sus organismos de vigilancia, especialmente al informe de la CIDH sobre "El acceso a la información en materia reproductiva desde una perspectiva de derechos humanos" y las interpretaciones del artículo 13 de la CADH sobre el derecho a la información en responsabilidad del Estado, como el Caso de Paulina del Carmen Ramírez Jacinto contra México del 8 de marzo de 2002.

35 Derecho a la información, interpretado por la Corte IDH como la posibilidad de acceder a la información que está bajo control del Estado.

36 Derecho de la mujer y el hombre a decidir libremente sobre el número de sus hijos e hijas y el intervalo entre los nacimientos.

37 Obligación de adoptar medidas para mejorar el acceso a la planificación de la familia, y obligación de abstención de limitar el acceso a los anticonceptivos. 
una perspectiva práctica, más fáctica que jurídica, quizás dando relevancia a estas situaciones que ponen a prueba permanentemente a las construcciones jurídicas $\mathrm{y}$, que además como elemento nuevo, exige irremediablemente un análisis con algún contenido moral y ético, resultando entonces tal respuesta del derecho como una especie de diagnóstico, o como una especie de radiografía del estado presente, de la cultura jurídica de una sociedad determinada, por lo menos en una época o tiempo determinado ${ }^{38}$, donde parece ser que la virtud epistemológica se prefiere a una especie de élite epistemológica (Dworkin, 2003; Nino, 1997).

Es claro que un caso desde estos términos, desde estos factores, finalmente en sede judicial, puede demostrar, justificar, verificar o resolver, diferentes posturas, atendiendo en la mayoría de los casos, a algún paradigma, pero sin lugar a dudas, sin aceptar las soluciones del positivismo paleontológico, e incluso, cuestionando implícitamente, el principio de subsunción, dada la dimensión del estudio que requiere este tipo de casos.

Uno de estos casos justiciables ${ }^{39}$, con tal repercusión ética, que enfrenta al derecho y cuya solución afecta a la sociedad, tiene que ver con las tensiones que se derivan de los derechos de la mujer gestante frente a los derechos de quien está por nacer, o de los derechos de los padres y el nasciturus frente a los prejuicios, la discrecionalidad judicial o la democracia deliberativa. El primer ejemplo puede ilustrarse más fácilmente, sin dejar de ser paradigmático, pues es el caso de la distancia entre la mujer y quien está por nacer, por lo tanto de sus derechos en conflicto. El segundo caso tiene que ver con la decisión de la materna y familia de garantizar y proteger a su hijo concebido frente a una decisión judicial o la Ley, y si es el caso, a lo que se decida después del nacimiento.

Aprovecho esta última tensión para aclarar la dimensión del problema que aquí se pretende describir, ya que es la de mayor implicación y complejidad, para lo

38 Son múltiples los casos que se pueden mencionar. Sin haber sido justiciable es relevante el caso de Lisa y Jack Nash - 2000 de Denver EE.UU., que celebraron contrato de servicios con Illinois Masonic Medical Center, para realizar pruebas de diagnóstico para implantación genética, análisis genético para elección de célula, y servicio de fertilización in vitro del embrión preseleccionado, con el fin de que se garantice que la extracción de las células madres de su cordón umbilical de Lisa sirvieran para ser donada a su hija Molly que presenta anemia de fanconi que es una patología de médula incurable, por lo que se requería que el embrión naciera con las células exactas y evitar su muerte por leucemia, pronosticada aproximadamente de manera general a los 7 años de vivir sin la enfermedad en su médula. Las perplejidades derivadas de este realismo son muchas, pero sus respuestas no han sido concretadas desde el derecho, al respecto han salido a deliberar muchos sectores, especialmente el de la medicina, que por ejemplo no incluye, sobre la moralidad, constitucionalidad y convencionalidad del procedimiento, el trato de los embriones seleccionados y especialmente de los sobrantes.

39 Uno de los múltiples casos justiciables en Europa que puede ser ejemplarizante, es el caso Alan y Louise Masterton de Escocia, 2000, en el Tribunal Europeo de Derechos Humanos, aquí se interpreta la Convención Europea de Derechos Humanos para determinar si existe el derecho de un matrimonio de elegir el sexo de su próximo hijo a través de la asistencia genética de selección embrionaria y posterior fecundación asistida, dado que la Ley vigente del Reino Unido prohíbe la elección del sexo. 
cual también doy cuenta de su justiciabilidad. Ilustro entonces el Caso de Jodie y Mary (2000), dirimido en el Reino Unido, en primera instancia, en el Tribunal de Apelación $^{40}$ de Londres, y en segunda instancia, ante la Alta Corte de Londres ${ }^{41}$. La situación debía resolver sobre la necesidad y la competencia para ordenar una intervención quirúrgica médica a unas gemelas siamesas que comparten su corazón, hijas de padres Turcos provenientes de la Isla de Gozo, y quienes viajaron a Londres en búsqueda de la mejor atención médica para lo que acudieron al Hospital Santa María de Manchester, y que, además, consideran como vida digna de sus hijas que les permitan vivir juntas así los diagnósticos prevean una vida corta.

Un caso donde se vincula la moral ${ }^{42}$, como se dijo, puede presentar distintas posturas, diferentes puntos de partida, y distintos resuelves. La justicia inglesa ordenó al Hospital de Manchester, dada la inviabilidad "duradera" de la supervivencia conjunta, realizar la intervención quirúrgica de separación de cuerpos, su argumento se basó en la obligación de proteger la vida de la niña que, según los diagnósticos, puede vivir y la necesidad de separar del cuerpo a quien se diagnosticó como la más débil. La decisión de separación de las niñas de tres meses de edad fue objeto de una decisión judicial, y del mismo modo se desestimó la pertinencia de los argumentos de sus padres, ya que su tesis parte de la defensa de la dignidad del derecho a la vida conjunta que implica asumir el riesgo de que sea corta. Se puede decir que los jueces defienden la tesis de que no se debe entregar una decisión a la moral de los representantes de las gemelas porque se incurriría en una falta grave deontológica, y alternamente una tesis que acepta la defensa de la vida si se entiende como vida digna y que el contenido de esta debe interpretarse por sus titulares o representantes y no por el Estado (se podría argumentar que la niña o los padres si demuestran daños, podrán a futuro demandar al Estado por no permitirle vivir bajo sus presupuestos de dignidad) imponiendo así estándares sociales, económicos ${ }^{43}$ y culturales. El caso

40 En este primer estudio existió cierta disertación, se presentaron y solicitaron varios estudios y conceptos médicos.

41 En esta instancia los tres magistrados decidieron de manera unánime conforme a la primera instancia.

42 Otro caso difícil es el de Francia, que refleja la complejidad de la temática, incluso cuando desde la deliberación procedimental se intenta limitar y garantizar libertades, aquí no se cuestiona el decisionismo judicial, sino el ejercicio legislativo. En Francia, la Asamblea Nacional, reformó recientemente la Ley Veil de 1975, incorporando el derecho a interrumpir el embarazo de niñas dentro de las primeras doce semanas de gestación, sin necesidad de autorización paternal, es decir, sin necesidad de informar y notificar del embarazo a la familia, solo debería asistir con un pariente o un asistente social hasta el centro médico especializado, lo cual incluiría la autorización de la administración de la píldora del día después hasta en los mismos centros de enfermería de los colegios. Esto involucra dimensiones éticas como, el fundamento mismo de la familia, sus tratos relacionales que involucran vínculos éticos y morales íntimamente relacionados con el funcionamiento social de la familia.

43 Se podrían presentar preguntas de este tipo: si ¿es justificable que un sistema de salud o de sanidad soporte, económicamente, la vida "inviable" de unas gemelas que comparten su corazón?, lo cual puede asemejarse al momento en que el derecho debió preguntarse si era justificables garantizar la vida, la salud y en general los derechos de los grupos étnicos indígenas, o al momento en que se preguntaba si los grupos afrodescendientes tradicionalmente esclavos y soporte de algún tipo de economía, deberían ser considerados como personas y por lo tanto, sujetos de derecho en igualdad de condiciones. 
no llegó a los Lores de la Ley dejando en firme lo resuelto en la segunda instancia ${ }^{44}$.

Como ya se ha dicho, tal vez de manera repetida, este caso pone cualquier norma jurídica, ética, e incluso moral, a prueba, cuya evaluación depende, de los estándares y cánones jurídicos, o bajo la racionalidad jurídica del futuro.

\section{REFERENCIAS}

Alexy, R. (1986). Theorie der Grundrechte. Prinzipien seien Optimierungsgebote. Frankfur: Suhrkamp Verlag.

Alexy, R. (2007). Teoría de los derechos fundamentales. Madrid: Centro de Estudios Políticos y Constitucionales. ( $2^{\mathrm{a}}$ ed. en castellano). (Trad. de Carlos Bernal Pulido).

Berlin, I. (2001). Dos conceptos de libertad y otros escritos. Madrid: Alianza Editorial.

Bonilla, D.; Iturralde M. (2005). Hacia un nuevo derecho constitucional. Bogotá: Universidad Externado de Colombia, Facultad de Derecho.

Carrillo, Y. (2009). Teorías de la argumentación y del razonamiento jurídico. Lugar y límites de la razón práctica en la fundamentación de las decisiones judiciales. Bogotá: Ediciones Doctrina y Ley.

Comité de Derechos Humanos de la ONU, sobre Igualdad de Derechos entre Hombres y Mujeres. Observación General No. 28 de marzo del 2000.

Consejo de Estado, Sala de lo Contencioso Administrativo, Sección Primera. Auto de 15 de octubre de 2008, doctora María Claudia Rojas Lasso, Expediente 200800256-00.

Corte Constitucional. Sentencia T-881 de 2002 M. P. Eduardo Montealegre Lynett.

Corte Constitucional. Sentencia T-988 de 2007 M. P. Humberto Sierra Porto.

Corte Constitucional. Sentencia T-209 de 2008 M. P. Clara Inés Vargas Hernández.

Corte Constitucional. Sentencia T-946 de 2008 M. P. Jaime Córdoba Triviño.

Corte Constitucional. Sentencia T-009 de 2009 M. P. Manual José Cepeda.

Corte Constitucional. Sentencia T-388 de 2009 M. P. Humberto Sierra Porto.

Corte Constitucional. Sentencia T-585 de 2010 M. P. Humberto Sierra Porto.

Corte Constitucional. Sentencia T-841 de 2011 M. P. Humberto Sierra Porto.

44 Organizaciones como PROVIDA que apoyaban la decisión de los padres, declararon que el recurso ante los Lores supone gastos millonarios que los padres no pueden sufragar y que de todos modos podría surtirse en un tiempo mínimo de cuatro semanas.

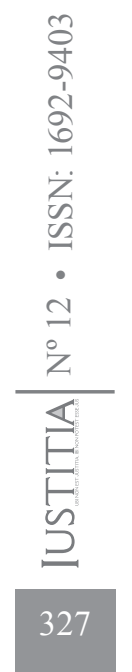


Corte Constitucional. Sentencia T-627 de 2012 M. P. Humberto Sierra Porto.

Dworkin, R. (2003). Virtud Soberana. La teoría y la práctica de la igualdad. Barcelona: Editorial Paidós.

Franco, D. (2012). La función hermenéutica constituyente de la Corte Constitucional. Una mirada a la luz de la conformación jurídica de familia. Revista de Fundamentación Jurídica Díkaion, 2(21), 407-429. Chía: Universidad de la Sabana.

Guerrero, F. (2010). Responsabilidad del Estado colombiano en el marco del derecho fundamental al territorio ancestral y su acceso a la justicia interamericana. Revista Iustitia, 8, 425-451. Bucaramanga: Universidad Santo Tomás Seccional Bucaramanga.

Guerrero, F. (2013). Píldoras para salvar la Constitución de 1991 (II parte). Procesos de constitucionalización en el imperio del hiperpresidencialismo. Revista Iustitia, 11, 299-322. Bucaramanga: Universidad Santo Tomás Seccional Bucaramanga.

Morano Cruz, R. (julio, 2009) ¿Qué nombra la moral?: El modelo deliberativo de Carlos Santiago Nino como alternativa a la disputa metaética entre la moral sustantiva y la procedimental. Revista de Filosofía, Derecho y Política, 10, 129149. Madrid: Universidad Carlos Tercero de Madrid.

Nino, C. S. (1997). La constitución de la democracia deliberativa. Barcelona: Editorial Gedisa.

Presidencia de la República de Colombia. Decreto 444 de 2006.

Procuraduría General de la Nación. Concepto 4024 del 1 de febrero de 2006.

Suárez, W. (2011). Racionalización, racionalidad material y decisiones judiciales. Revista Iustitia, 9, 243-261. Bucaramanga: Universidad Santo Tomás Seccional Bucaramanga. 